\title{
Comunicación de datos presupuestarios de administraciones públicas mediante visualización: uso de la aplicación "Dónde van mis impuestos"
}

\author{
Communicating public administration budget data \\ through visualization software: Use of the tool \\ 'Where do my taxes go'
}

\author{
Jesús García-García; María-Isabel Alonso-Magdaleno
}

Cómo citar este artículo:

García-García, Jesús; Alonso-Magdaleno, María-Isabel (2020). “Comunicación de datos presupuestarios de administraciones públicas mediante visualización: uso de la aplicación 'Dónde van mis impuestos'”. El profesional de la información, v. 29, n. 1, e290117.

https://doi.org/10.3145/epi.2020.ene.17

Artículo recibido el 30-07-2019 Aceptación definitiva: 18-11-2019

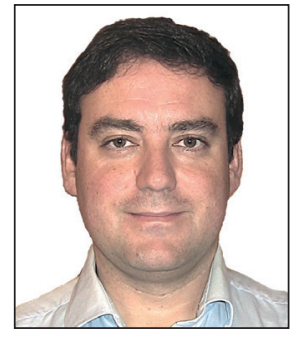

Jesús García-García $\square$
https://orcid.org/0000-0002-5120-8851
Universidad de Oviedo
Facultad de Economía y Empresa
Departamento de Contabilidad
Avenida del Cristo, s/n.
33006 Oviedo, España
jesgar@uniovi.es

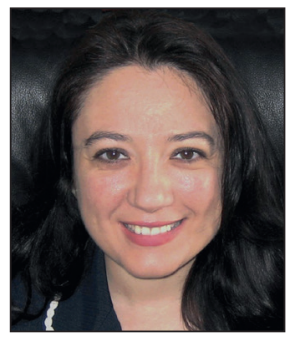

María-Isabel Alonso-Magdaleno https://orcid.org/0000-0002-4865-1561

Universidad de Oviedo

Facultad de Economía y Empresa

Departamento de Adm. de Empresas

Avenida del Cristo, $\mathrm{s} / \mathrm{n}$.

33006 Oviedo, España

ialonso@uniovi.es

\section{Resumen}

Los programas de visualización presupuestaria facilitan la comunicación de informaciones técnicas complejas. En el artículo analizamos los principales factores técnicos, individuales y organizativos que afectan a su implementación y uso. Mediante cuestionario hemos recogido datos de los responsables de la aplicación web “Dónde van mis impuestos" en 23 administraciones autonómicas y locales españolas. El análisis de resultados nos permite afirmar que estas aplicaciones informáticas tienen un reducido número de usuarios, pero que sus principales destinatarios no son la ciudadanía sino grupos particulares, principalmente medios de comunicación y agrupaciones políticas. Su adopción no es un problema presupuestario ni tecnológico, aunque una licencia de software libre otorga claras ventajas. El impulso para la adopción es principalmente político con un objetivo de transparencia financiera y presupuestaria, pero en ocasiones también de transparencia participativa o microtransparencia. Por último, en su gestión detectamos un serio riesgo de gobernanza generado por la falta de estrategias claras de transparencia y rendición de cuentas en las administraciones, así como una ausencia de procedimientos operativos para adaptarse a la cambiante estructura presupuestaria.

\section{Palabras clave}

Visualización de datos; Visualización de información; Información pública; Presupuesto; Administración pública; Innovación pública; Sitios web; Webs; Software; Aplicaciones; Transparencia; Datos; Datos abiertos.

\begin{abstract}
Budget visualization tools facilitate the communication of complex technical information. In this paper, we analyse the main technical, individual and organizational factors that affect its implementation and use. Through a questionnaire survey we have collected data from those responsible for the web application "Dónde van mis impuestos" ("Where do my taxes go?") in 23 Spanish regional and local governments. Our findings show that these tools have a small number of users but that their main target are not citizens but specific groups, mainly media and political groups. Its adoption is neither a budgetary nor technological problem, although the free software license gives clear advantages. The impulse
\end{abstract}


for adoption is mainly political with the main focus on financial and budgetary transparency but sometimes also on participatory transparency or microtransparency. Finally, we detect a serious risk of governance generated by the lack of clear transparency and accountability strategies in the administrations, as well as an absence of operational procedures to adapt to the changing budgetary structure.

\section{Keywords}

Data visualization; Information visualization; Public information; Budget; Public administration; Public innovation; Web sites; Webs; Software; Transparency; Data; Open data.

\section{Introducción}

El presupuesto es un instrumento básico de gestión pública que supone la expresión económica, financiera y contable detallada de las políticas llevadas a cabo por una administración durante un año natural, tanto a nivel de previsión como de ejecución realizada. Su esencia se encuentra en el corazón mismo del proceso democrático de legitimidad y rendición de cuentas, plasmando la relación entre los recursos que una administración pública obtiene de los ciudadanos y el uso que se hace de ellos. Se evita de este modo el ejercicio arbitrario y abusivo del poder y se asegura un funcionamiento eficiente y eficaz del sector público. Por ello debería ser de uso frecuente para el debate de lo público, manejable por amplios sectores de la población, comprensible en sus contenidos y fácilmente accesible en sus formatos digitales. La realidad es que su acceso se produce a través de documentos con formas y contenidos difícilmente inteligibles para el ciudadano medio, ya que prima su función como herramienta de gestión de los recursos públicos en detrimento de una comunicación efectiva para impulsar su papel en la rendición de cuentas.

El concepto de gobierno abierto, con su énfasis en los datos públicos abiertos como fuente de transparencia, participación y colaboración, ha sido en los últimos tiempos el paradigma fundamental para la rendición de cuentas de las administraciones públicas. Multitud de datos han pasado a estar a disposición del público en formatos digitales reutilizables y con licencia abierta. Con base en ellos, terceros ajenos a la administración pública han podido construir aplicaciones, visualizaciones o informaciones. Resulta evidente que estos datos abiertos no deben hurtarse al público, particularmente por la relativa sencillez de su divulgación, pero esta simplicidad puede convertir la publicación en un fin y no en un medio. Corremos el riesgo de que la problemática se reduzca a "subir la hoja de cálculo" sin ninguna evaluación de la demanda de los datos o del valor de lo ofrecido para la sociedad. Al mismo tiempo, el mito del dato abierto como "dato en crudo", que implícitamente atribuye absoluta neutralidad para su uso, pudiera sesgar la

Nos arriesgamos a que los datos abiertos se reduzcan a "subir la hoja de cálculo" sin ninguna evaluación de su demanda o del valor de lo ofrecido para la sociedad problemática de la rendición de cuentas hacia una élite de usuarios capacitados para su manejo y tratamiento. Creemos que no existe esa neutralidad, pues desde el momento en que se opta por qué, cómo y cuándo se recoge un dato y de qué forma se presenta al público, tenemos decisiones humanas con impacto en las conclusiones que se pueden extraer de ellos. Por ello, si bien no deben abdicar de su labor y deber de divulgar, las administraciones deben convertirse en los primeros reutilizadores de sus datos con el fin de cumplir con su obligación de rendir cuentas del modo más eficiente y eficaz posible, particularmente con el objetivo de hacerlo ante amplios sectores de la población.

Con esta motivación, abordamos el estudio de la adopción y uso de aplicaciones gráficas de visualización de información presupuestaria. Se dice que "una imagen vale más que mil palabras", y por ese procedimiento estas aplicaciones convierten en accesibles los presupuestos, haciendo uso de figuras geométricas proporcionales para representar visiones globales y los pesos de distintas actuaciones, en las que se puede ir descendiendo jerárquicamente en su desglose al mismo tiempo que se observan las cifras y se obtienen evoluciones interanuales. Nuestro estudio trata el uso y utilidad de las aplicaciones de visualización sobre datos presupuestarios en las administraciones públicas españolas. Con él se pretende mejorar el conocimiento sobre qué lleva a una administración pública a adoptar este tipo de software y cómo enmarcamos esta decisión en el marco general de datos abiertos, transparencia y rendición de cuentas. En la bibliografía académica ya existen estudios sobre implantación y contenidos de portales de transparencia en general, y particularmente centrados en España. El presente trabajo aporta como novedad una focalización específica a los datos presupuestarios y a un software para mejorar su comunicación hacia los usuarios finales.

En los siguientes apartados plantearemos un breve marco teórico que nos sirva de apoyo al estudio de la cuestión, tanto desde la óptica de la divulgación informativa como de la adopción tecnológica. Posteriormente, plantearemos la metodología en la que nos hemos basado para obtener evidencia empírica sobre el fenómeno. Por último, expondremos los resultados y conclusiones obtenidas.

\section{Antecedentes y estado actual del tema}

En primer lugar se expone el estado de la cuestión respecto a la divulgación de información presupuestaria, particularmente basada en datos abiertos, en un entorno de creciente desinformación. Posteriormente nos centramos en la fundamentación teórica de la adopción tecnológica sobre la que basamos parte del cuestionario empleado en la investigación. 


\subsection{Procesos verticales de rendición de cuentas}

Siguiendo el modelo clásico de O’Donell (1994), la rendición de cuentas se puede establecer horizontal o verticalmente.

El modelo horizontal se refiere a las condiciones autoimpuestas por el gobierno, principalmente por unos órganos sobre otros, por ejemplo, intervención, fiscalización o control externo. En una sociedad democrática supone indirectamente un control y rendición de cuentas a la ciudadanía, pero con expertos y elementos técnicos interpuestos que convierten sus informaciones en lejanas y de difícil comprensión.

El modelo vertical es en puridad el control y rendición de cuentas directo a los ciudadanos, que reaccionarían con aprobación o desaprobación de las propuestas y actuaciones mediante el uso de canales participativos de debate público, acciones de protesta o apoyo y, en última instancia, el proceso electoral. La verticalidad no excluye el uso de intermediarios ajenos a gobierno y administración, principalmente medios de comunicación y colectivos ciudadanos, o el denominado activismo de datos (Fuchs, 2010; Gutiérrez, 2018), que pueden incluso hacer uso de En un escenario de creciente desinformación, la primera cifra que se recibe ancla el pensamiento y condiciona la conducta del receptor informaciones generadas en los procesos horizontales.

No obstante, en la actualidad observamos cómo el proceso vertical de rendición de cuentas se encuentra condicionado por fenómenos como las denominadas fake news, informaciones inventadas que replican las formas de divulgación clásicas de los medios de comunicación pero no sus procesos internos editoriales para asegurar la corrección y credibilidad (Lazer et al., 2018). Algunos autores prefieren como más riguroso el término "desinformación", refiriéndose al proceso más que a la noticia concreta, por considerar que fake news no captura toda la complejidad de las formas de manipulación informativa (Nielsen; Graves, 2017; Rodríguez-Fernández, 2019) y, particularmente, aquella información que no es propiamente falsa sino incorrecta, parcial, errónea, tendenciosa o engañosa. La desinformación siempre ha estado presente en la sociedad, pero ha adquirido niveles de complejidad y escala sin precedentes en nuestro escenario interconectado y crecientemente polarizado (Wardle; Derakhshan, 2017), fomentada por la enorme disminución de las barreras de entrada a la publicación y la divulgación periodística y por el respaldo y apoyo implícito que constituyen la compartición y los me gusta en redes sociales. Este tipo de informaciones se difunden por medios digitales mucho más rápidamente y por más personas que las informaciones veraces, particularmente cuando su temática es de carácter político (Vosoughi; Roy; Aral, 2018). Destaca en este sentido el concepto de meme como idea contagiosa que logra captar la atención y guiar el comportamiento y opinión basándose en las emociones humanas y que está cada vez más presente en el debate político (Rodríguez, 2013). Es especialmente relevante cuando en el debate hay cifras de por medio, como es el caso de las magnitudes económicas, financieras y presupuestarias de los gobiernos, debido al fenómeno denominado "efecto ancla" (Kahneman, 2016) consistente en que la primera cifra que se recibe "ancla" el pensamiento y condiciona la conducta del receptor. En un mundo de abundancia de datos, al que las administraciones públicas se han sumado, ofrecer datos e informaciones de una forma accesible y contextualizada se convierte casi en una obligación para conseguir los objetivos de transparencia y rendición de cuentas inherentes a cualquier gobierno. A este fin se han de buscar los métodos y herramientas de comunicación que mejor combatan los problemas de información anteriormente mencionados.

Dentro del modelo vertical de rendición de cuentas, en los últimos años hemos asistido al auge del gobierno abierto; un nuevo escenario de relación entre gobiernos y ciudadanos basado en la transparencia para fomentar la participación y la colaboración entre ambos. Los datos abiertos u open data son su herramienta esencial, alterando el equilibrio de información en favor del ciudadano en la problemática de agencia en que se enmarcan transparencia y control (García-García, 2014).

Existen numerosas definiciones de datos abiertos presupuestarios y políticas de gobierno abierto. Clarke y Francoli (2014) y Gray (2015) presentan sendos compendios, centrados en los aspectos legales y técnicos. Hay un elevado consenso en las definiciones, pero no tanto respecto a su utilidad oscilando las visiones entre un extremo de transparencia financiera importante por sí misma, independientemente del método, y otro extremo de datos abiertos importantes como herramienta con independencia de para qué se usen. En palabras de Gray (2015) este abanico podría responder a las diferentes agendas y visiones de la política fiscal. En cualquier caso, los datos presupuestarios fueron de los primeros en seguir este camino de libre divulgación en la Red, bien como simples datos, primero en las webs institucionales y luego en portales de trans-

Los expertos y medios de comunicación pueden ver facilitada su labor de canalizadores de información a la ciudadanía haciendo uso de estas herramientas

parencia (principalmente documentos PDF conteniendo los presupuestos íntegros), o bien como open data en los portales de datos abiertos (formatos estructurados bajo licencias que permiten su libre reutilización). Como investigadores llevamos ya largos años centrándonos en el estudio de la divulgación basada en la tecnología digital y datos abiertos y, en nuestra experiencia, coincidimos con los diagnósticos de: 
- Heald (2012): en lo que denomina el problema de los missing users (usuarios perdidos) en referencia a la brecha entre expectativas y uso real de la información puesta a disposición del público.

- Meijer (2013): se refiere a la relación entre transparencia y rendición de cuentas como un problema de caja negra, en tanto que pareciendo que existe una estrecha relación entre ambas, realmente la bibliografía académica y los análisis de casos prácticos no han podido ofrecer una evaluación generalizada de sus efectos.

- Gray (2015): señala el nulo análisis de la demanda de información presupuestaria suministrada como datos abiertos y el amplio desconocimiento existente sobre cómo, para qué y con qué fin se usa.

- Worthy (2015): para el Reino Unido recoge la necesidad señalada en entrevistas personales, tanto por el gobierno británico como por usuarios de la información presupuestaria, de disponer de herramientas accesibles y sencillas para los usuarios que permitan localizar y visualizar la información en un contexto.

Los diagnósticos apuntan todos en un mismo sentido. A pesar de divulgar información, no se está usando lo suficiente. Además desconocemos cuál es el mecanismo por el que causa sus efectos y desconocemos qué quieren exactamente los ciudadanos; aunque parece que demandarían una información sencilla, accesible y contextualizada. Esto último es lo que pueden ofrecer las aplicaciones gráficas de visualización de la información presupuestaria en la Web. Los datos abiertos tienen como objetivo facilitar

Las herramientas de visualización ofrecen una información sencilla, accesible y contextualizable

su reutilización para elaborar informaciones o visualizaciones más complejas. También presuponen que el usuario que accede a ellos tiene conocimientos presupuestarios y sobre el software para poder operar con ellos.

Por el contrario, la visualización de información permite que datos complejos puedan cobrar sentido y, como complemento a las representaciones textuales o verbales, ofrecen un amplio potencial para servir de apoyo al conocimiento y a la comunicación en temas complejos como son los presupuestos de las administraciones publicas. Su objetivo principal es facilitar la comprensión a personas no versadas en la materia de las cantidades consignadas para determinadas políticas y partidas. Para ello se sirven de una vista global de los gastos e ingresos a partir de la cual se puede ir descendiendo jerárquicamente de mayor a menor nivel de detalle, examinar la participación sobre el total y su evolución temporal, y comparar con otras políticas y partidas del mismo período o anteriores.

Es por ello que una de las funciones más frecuentes de los datos presupuestarios abiertos ha sido crear visualizaciones, tanto desde las propias administraciones como desde el activismo de datos. Fundamentalmente, a través del software libre generado en los proyectos:

- Where does my money goes?

http://app.wheredoesmymoneygo.org

- Open spending

https://openspending.org

- OffenerHaushalt

https://offenerhaushalt.de

- Open budget

http://make.opendata.ch/wiki/project:open_budget

de la asociación Open Knowledge y sus adaptaciones a los entornos locales, pero también a través de portales de software privativo elaborados para administraciones públicas por las empresas OpenGov y Socrata.

https://opengov.com

https://socrata.com

Es especialmente destacable que, aunque sea facilitado en la descarga de los datos como abiertos, se abstrae parcialmente la complejidad de la información técnica presupuestaria centrando la visualización en políticas (estructura económica y funcional del presupuesto: cómo se gasta y en qué se gasta) en vez de en órganos de ejecución presupuestaria (estructura orgánica).

A modo de ejemplos se pueden consultar las aplicaciones:

- Presupuestos abiertos del Ayuntamiento de Madrid

https://presupuestosabiertos.madrid.es/es

- Presupuestos de Aragón

https://presupuesto.aragon.es

Resulta evidente que este tipo de aplicaciones gráficas facilitan el examen, la comparación y la contextualización de la información a personas con menores conocimientos en materia presupuestaria. En el caso de los conjuntos de datos abiertos, tal y como se ha expuesto, el grado de reutilización que permiten de la información es mayor, pero requieren de un cierto conocimiento informático de tratamientos de datos. Véase a modo de ejemplo:

- Presupuesto de gastos del Ayuntamiento de Gijón 2018 http://transparencia.gijon.es/set/economia/presupuestos_gastos_ayto_2018 


\section{- Presupuestos generales de Navarra}

https://gobiernoabierto.navarra.es/es/open-data/datos/presupuestos-generales-navarra-2019

No obstante, ambas formas de divulgar son preferibles al clásico documento PDF, que exige de conocimientos presupuestarios para su comprensión, no permite un sencillo examen, comparación o contextualización, además no permite su tratamiento con herramientas digitales para extraer datos y construir informaciones. Véase por ejemplo:

- Presupuestos generales del Principado de Asturias 2019

https://tematico.asturias.es/presupuestos/2019/Presupuestos/TOMO_I.htm

\subsection{Adopción de la innovación tecnológica}

Las herramientas de visualización son aparentemente accesibles para las administraciones públicas como software libre, y responden a una demanda de información asequible en su comprensión, así como contextualizable en las magnitudes para el ciudadano medio. Pretendemos profundizar en el conocimiento acerca de su adopción y uso y para ello las situamos en el plano de las innovaciones en las administraciones públicas, distinguiendo la innovación pública propiamente dicha de la innovación social (Edwards-Schachter; Matti; Alcántara, 2012):

- Innovación pública: el proceso de innovación se produce dentro de la administración respondiendo tanto a incentivos internos como externos (demandas sociales).

- Innovación social: la iniciativa parte de la ciudadanía, aunque las administraciones e incluso el sector privado puedan brindar apoyo, colaboración o participación.

Esta frontera también se vuelve permeable cuando hablamos de innovación pública abierta, considerada como un proceso de generación de nuevas ideas, prácticas y herramientas que no sólo se nutre de los recursos internos de las administraciones públicas, sino que integra al conjunto de la sociedad en su generación, en la línea del concepto descrito por Chesbrough (2003) para el sector privado. En todo caso, este proceso innovador deberá implicar siempre ideas parcialmente nuevas y no sólo mejoras, que sean ejecutadas en la práctica y no se queden en el campo conceptual, así como que tengan realmente un impacto positivo en la creación de valor público (Mulgan, 2007).

Existen múltiples teorías cuyo objetivo es explicar la adopción de una tecnología o innovación concreta por usuarios individuales u organizaciones, pero previamente debemos considerar que el uso de una herramienta se corresponde con la consecución de unos fines. No estaríamos hablando en este momento de factores propiamente enunciados en teorías de adopción tecnológica, sino en la práctica sobre divulgación de información contable y presupuestaria y datos abiertos. Para su enunciado nos hemos basado fundamentalmente en el estudio de Worthy (2015) sobre el impacto de los datos abiertos en Reino Unido. Encontramos en este apartado explicaciones de divulgación como respuesta a la demanda ciudadana, simplemente de información, o también de datos para reutilizar en procesos de participación y colaboración, cumpliendo con unos plazos de tiempo oportunos a la naturaleza de la información divulgada. También el tipo de información que se divulga; entre la más destacada en la normativa y práctica en España nos encontramos con presupuestos y ejecuciones, listas de gastos, gráficos explicativos, saldos bancarios o datos de contratación. Asimismo resulta de interés conocer los destinatarios de la información divulgada. En este caso hemos optado por mejorar la lista de Worthy (2015) incluyendo a los partidos políticos y empresas contratistas en vez de usar la lista de usuarios de la información contable pública incluida en el Plan General de Contabilidad Pública de 2010, ya que en palabras de la IGAE

"entre los destinatarios de la contabilidad pública se abre una gama muy amplia de colectivos (...) en general, cuantos colectivos se vean afectados de una u otra manera por la actividad económico-financiera del sector público, que prácticamente son, por una u otra razón, y desde diferentes ópticas, todos los que componen el tejido político, económico e institucional de la sociedad" (IGAE, 1991).

Por último, tenemos en cuenta las potenciales barreras que pueden dificultar o impedir la implantación de una tecnología y que, de nuevo con base en Worthy (2015), consideramos que son:

- resistencia jerárquica;

- falta de capacidad tecnológica en hardware o software;

- falta de recursos humanos;

- dinámica cultural pobre;

- ausencia de una estrategia clara en transparencia y rendición de cuentas;

- fata de disponibilidad presupuestaria.

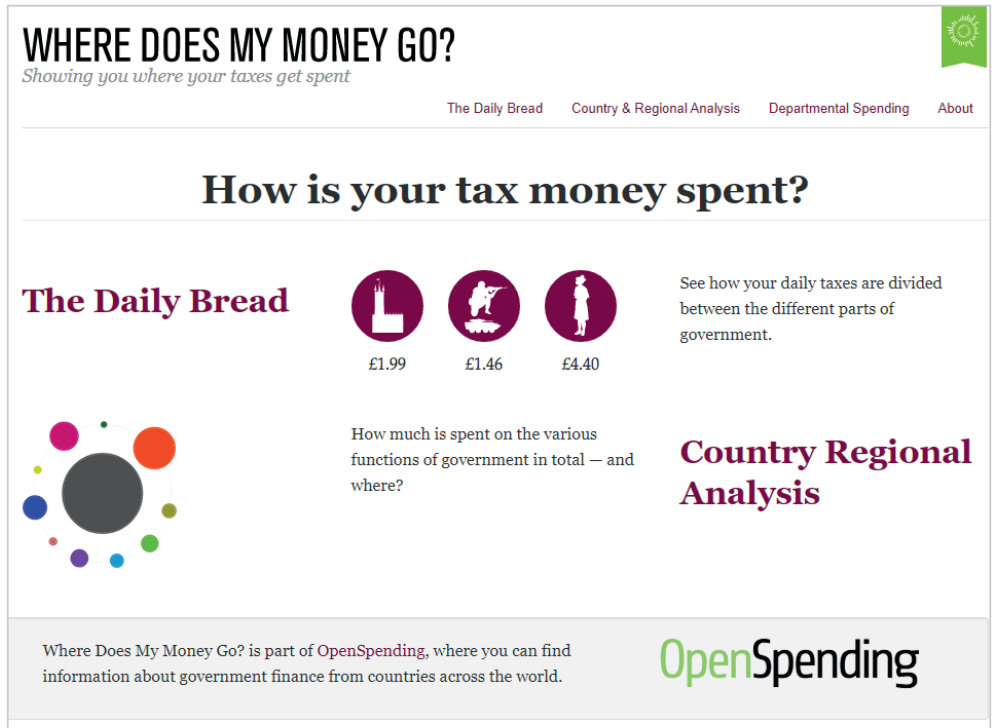

http://app.wheredoesmymoneygo.org 
Centrándonos exclusivamente en la bibliografía sobre adopción de nuevas tecnologías, existen múltiples teorías explicativas. Una primera división es entre explicaciones de carácter conductista y de carácter ambiental.

Las teorías conductistas suponen que cuando alguien tiene una intención de actuar, será libre de actuar sin limitaciones. Este es esencialmente el postulado de la Teoría de la acción razonada, las actitudes estarían determinadas por las creencias que los observadores asocian con un objeto y todos los individuos valorarán sus creencias para formar actitudes y ejecutar acciones, pero estas creencias serán distintas según el individuo. Las creencias basadas en experiencias directas con el objeto son más accesibles que las creencias basadas en experiencias indirectas, por lo que en el primer caso las actitudes correspondientes predicen mejor las conductas basadas en ellas que las previstas en el segundo caso (Fishbein; Ajzen, 1975; Ajzen; Fishbein, 1977). No obstante, es evidente que el mero deseo de actuar no es suficiente para explicar la conducta, pues pueden existir limitaciones para su ejecución. En este punto la Teoría de aceptación de la tecnología extiende los postulados anteriores, pues explica que ante una nueva tecnología existe un conjunto de factores que determinan la decisión sobre cuándo y cómo se utilizará. Los factores condicionantes de la conducta de adopción no basados en creencias previas son principalmente la utilidad esperada de la tecnología y la facilidad percibida de uso (Davis, 1989; Bagozzi; Davis; Warshaw, 1992; Venkatesh; Davis, 2000) y se han mostrado en diversos contextos como determinantes para conocer la aceptación de la tecnología (Turner et al., 2010; Marangunić; Granić, 2015).

Paralelamente a ésta, la Teoría del comportamiento planeado trata de explicar también el comportamiento deliberado, teniendo en cuenta que puede no ser completamente voluntario o estar bajo total control del sujeto, y sería conducido por:

- creencias de comportamiento: referidas a las consecuencias probables del comportamiento;

- creencias normativas: sobre la presión social percibida o norma subjetiva;

- creencias controladas: sobre factores que puedan facilitar o impedir el desempeño del comportamiento (Ajzen, 1985; 1991).

Estas tres creencias combinadas conducen a la formación de un comportamiento intencional en la adopción tecnológica. Como regla general, cuanto más favorable la actitud y la norma subjetiva mayor será el control percibido y, consecuentemente, mayor será la intención de adopción tecnológica, que además se vería reforzada residualmente por comportamientos pasados sobre otras adopciones tecnológicas previas (Ajzen, 2002).

Finalmente, ligado a las consecuencias probables del comportamiento, la Teoría de la motivación (McClelland, 1987), establece entre otras las necesidades de excelencia en el desempeño, afiliación grupal e incremento de poder organizacional como motores complementarios de la conducta.

Las teorías de carácter ambiental no se basan en características subjetivas de las personas responsables de la implementación tecnológica, sino en las características objetivas de la organización que realiza la adopción. El marco teórico tecnología-organización-ambiente explica cómo el proceso por el cual una entidad implementa innovaciones tecnológicas se ve influido por el contexto tecnológico, organizativo y ambiental (DePietro; Wiarda; Fleischer, 1990; Baker, 2012). El contexto tecnológico incluye tecnologías internas y externas a la organización, y tanto activos como procesos. El organizativo se refiere a las características y recursos de la organización como tamaño, centralización, formalización, estructura directiva, recursos humanos, principales recursos escasos y relaciones internas y externas. Finalmente, el ambiental comprende el marco externo general en el que opera la organización y, en el caso en estudio, el marco regulatorio y de buenas prácticas.

Por último, debemos considerar también la Teoría de difusión de la innovación que explica cómo, por qué y a qué ritmo se expanden las nuevas ideas y tecnología en el tiempo en un proceso de comunicación social (Rogers, 2003). Parte de sus factores explicativos se pueden considerar incluidos a grandes rasgos en las teorías previamente expuestas. No obstante, consideramos de interés los factores explicativos referidos al papel del liderazgo en el proceso (basado en autoridad, en influencia o en consenso) y a la necesidad de un seguimiento para la confirmación de la idoneidad del proceso innovador, que no se encuentran claramente definidos en las teorías previas. Para interpretar los resultados recogidos con base en cualquiera de estas teorías de adopción tecnológica debemos ser siempre cautelosos, pues como alerta Rogers, existirán potenciales sesgos de observación debido a la actitud generalmente positiva hacia la innovación.

\section{Metodología}

Hemos focalizado nuestra investigación en la aplicación de visualización denominada iPresupuesto Abierto de Aragón - Aragón Open Budget! financiada por el proyecto Aragón Open Data por ser la más extendida en las administraciones públicas españolas.

https://github.com/aragonopendata/presupuesto

La aplicación tiene licencia de software libre European Union Public Licence 1.1 que otorga libertad de uso, reutilización, adaptación y modificación, con la única condición de mantener el código fuente resultante también como software libre. Con frecuencia, esta aplicación se encuentra también denominada como Dónde van mis impuestos, nombre empleado por la Fundación Civio, que fue su creador para el proyecto Aragón Open Data y que realiza la mayor parte de las adaptaciones para las administraciones españolas, que pueden encontrarse en su repositorio de GitHub.

https://github.com/civio 
Esta última denominación es la que, generalmente, se encuentra en las webs institucionales para la aplicación, combinada con otras como por ejemplo Cuentas claras o Presupuestos visuales. El desarrollo del código fuente de esta herramienta se enmarca en el plano de las innovaciones sociales, si bien su rápida adopción por el sector público hace que comparta rasgos de innovación pública abierta.

La determinación de la población objeto de estudio se ha centrado en la aplicación con independencia del nombre que reciba por parte de la administración, y la forman las 32 administraciones públicas españolas que en mayo de 2019 la tenían en uso en su web institucional y la mantenían actualizada (véase anexo 1: 6 comunidades autónomas, 24 ayuntamientos y 2 consejos insulares). La cobertura es de cerca de 17 millones de habitantes, algo más de un tercio de la población española, que pueden emplear la aplicación para visualizar los presupuestos de sus administraciones locales y/o autonómicas.

Como instrumento de investigación se emplea un cuestionario de 16 preguntas estructuradas (anexo 2), principalmente escalas Likert de 1 a 5 o respuesta múltiple e incluyendo respuesta abierta cuando proceda. Estas preguntas fueron

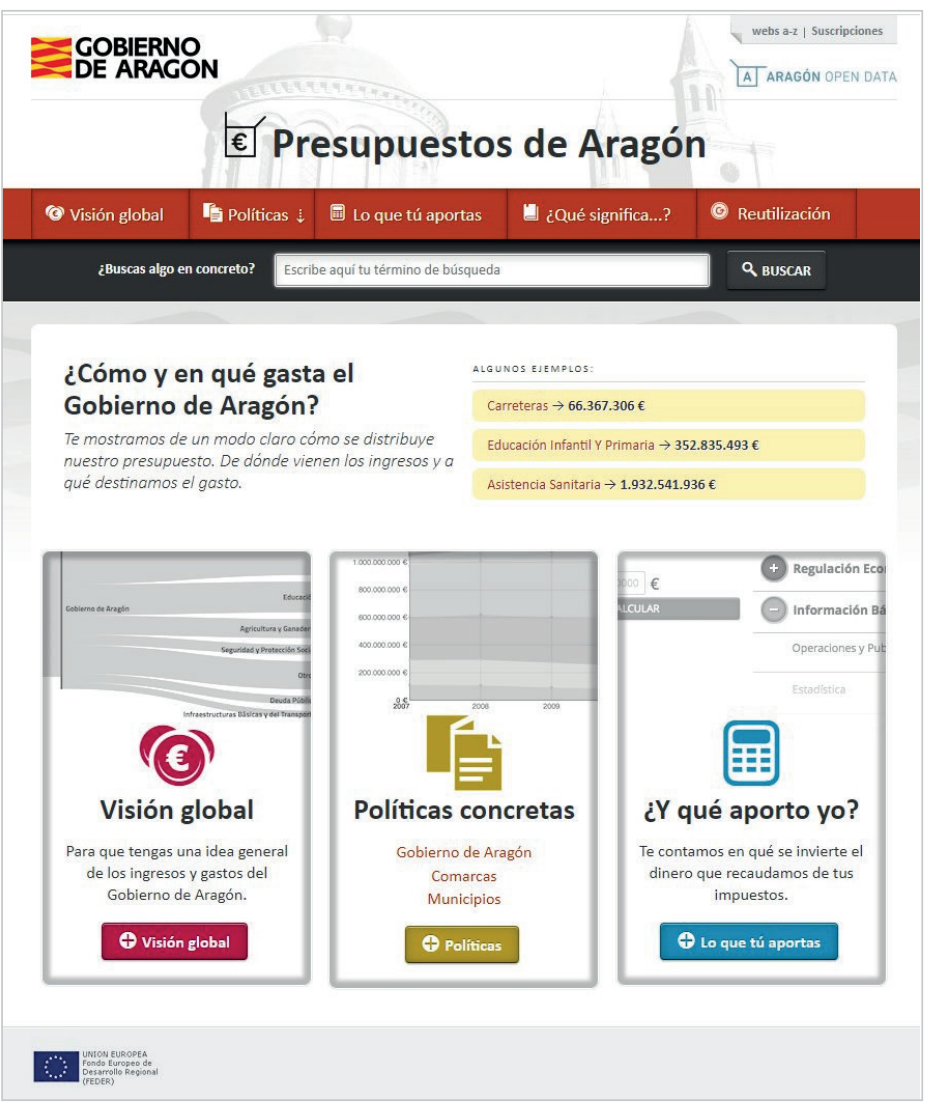

https://presupuesto.aragon.es elaboradas sobre la base de la fundamentación teórica expuesta en el apartado anterior. Se agruparon en tres bloques (general, actitudes individuales y contextos) simplemente por operatividad del cuestionario. Las preguntas del bloque general se basaron principalmente en el estudio de Worthy (2015) para importancia subjetiva y atribuida para la administración de ciertos factores en la divulgación (P1 y P2), grupos de usuarios (P4) y barreras a la adopción (P5); y en la práctica divulgativa de las administraciones públicas para la importancia de los contenidos (P3). En el bloque de actitudes individuales se basan:

- en la Teoría de la acción razonada las preguntas sobre creencias previas respecto al tipo de transparencia generada (P6) y experiencia en el uso de la tecnología y datos abiertos (P7A y P7B);

- en la Teoría de aceptación de la tecnología las preguntas sobre utilidad percibida de la herramienta (P8A, P8B, P8C y P8D) y facilidad percibida en la implementación (P9A, P9B, P9C y P9D);

- en la Teoría de la motivación y la Teoría del comportamiento planeado las preguntas sobre motivaciones personales para la implementación (P10A y P10B);

- en el marco tecnología-organización-ambiente las preguntas sobre capacidad tecnológica (P11), acceso a la tecnología (P12A y P12B), variables de entorno organizativo (P13) y marco regulatorio y proactividad (P14);

- en la Teoría de difusión de la innovación las preguntas sobre tipo de liderazgo (P15) y seguimiento (P16).

Antes de su difusión, el cuestionario fue probado con expertos en la materia para verificar su pertinencia y funcionalidad.

El cuestionario se dirigió a los responsables de la aplicación de visualización, definidos como aquella persona con capacidad de decisión y responsabilidad sobre la misma, su implantación, mantenimiento, actualización o retirada. A lo largo del mes de mayo se le hizo llegar al responsable de cada administración por correo electrónico, facilitando un URL para la recogida de datos, y posteriormente por correo postal a aquellas entidades de las que no se hubiera obtenido respuesta tras un recordatorio. La recogida de respuestas ha-

En mayo de 2019, 32 administraciones españolas tenían en uso el sistema de visualización en su web institucional

bía finalizado días antes de la constitución de los nuevos gobiernos surgidos de las elecciones locales y autonómicas del 26 de mayo, evitando así potenciales interferencias por la llegada de nuevos responsables. La tasa de respuesta fue en total de 23 entidades, de las 32 que integraban la población en estudio, la totalidad de las comunidades autónomas y un 70,83\% de los ayuntamientos (6 comunidades autónomas y 17 ayuntamientos).

A continuación analizamos los resultados obtenidos en los diferentes apartados conforme a los objetivos propuestos. 


\section{Resultados}

\subsection{Bloque general}

En este apartado se perfila una serie de características genéricas relativas a la divulgación de información de las administraciones, particularmente presupuestaria, y a las barreras que le pueden afectar.

\subsubsection{Importancia de algunos factores para publicar la información}

Para iniciar el cuestionario se hacían dos preguntas sobre la importancia concedida a tres factores (gráfico 1) a la hora de publicar información.

La primera pregunta era sobre la importancia que les concedía el encuestado y la segunda sobre la importancia que el encuestado creía que les atribuía su entidad, valorando de 1 a 5 de poco a muy importante. Como muestra la figura 1 , para los tres factores los responsables de la aplicación les atribuían mayor importancia que la que creían les concedía la entidad.

No existen grandes diferencias entre los factores, tanto para los valorados por los encuestados como por los atribuidos a la entidad, pero sí se produce una brecha de expectativas entre ambos. La mayor de ellas en la divulgación en formatos abiertos para la reutilización, que es al mismo tiempo el más valorado por los encuestados pero el que menos importancia consideran que le atribuye su entidad. En ningún caso se producían desviaciones típicas anormales, aunque eran mayores en el caso de las respuestas sobre importancia atribuida por la entidad. En la importancia otorgada por los responsables a la divulgación en formatos abiertos $(4,65)$ la desviación típica fue extraordinariamente reducida $(0,48)$, indicando un elevado consenso.

\subsubsection{Importancia concedida a los contenidos}

En el cuestionario se preguntaba a los responsables por la relevancia

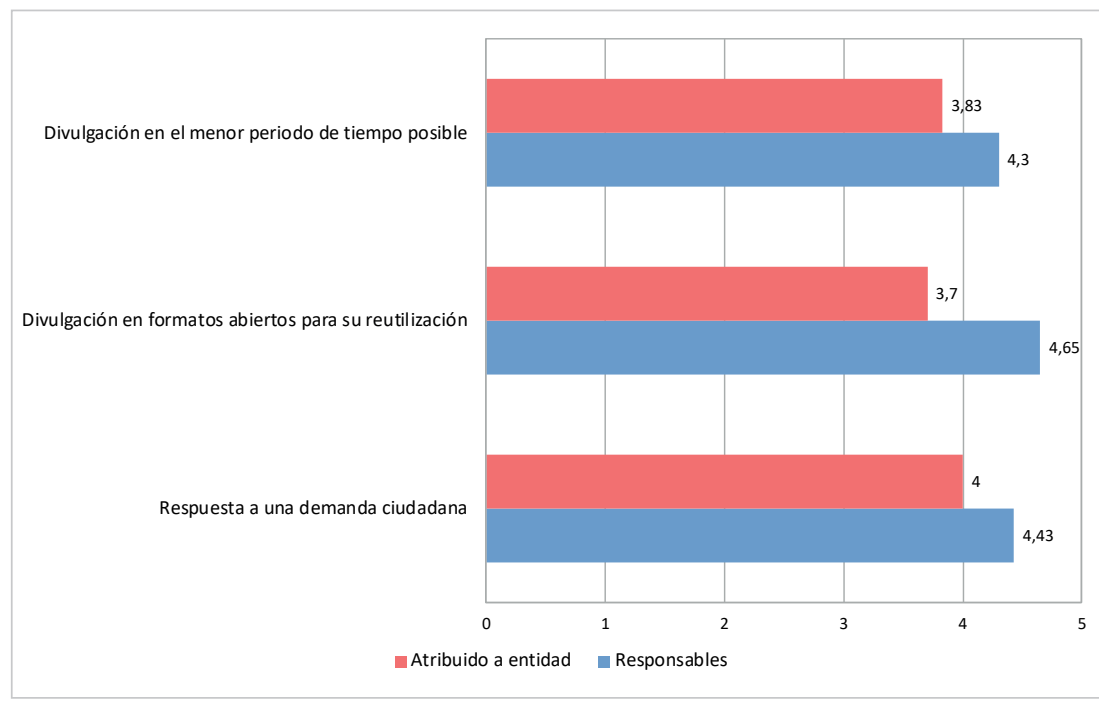

Gráfico 1. Importancia de factores para publicar la información (promedio)

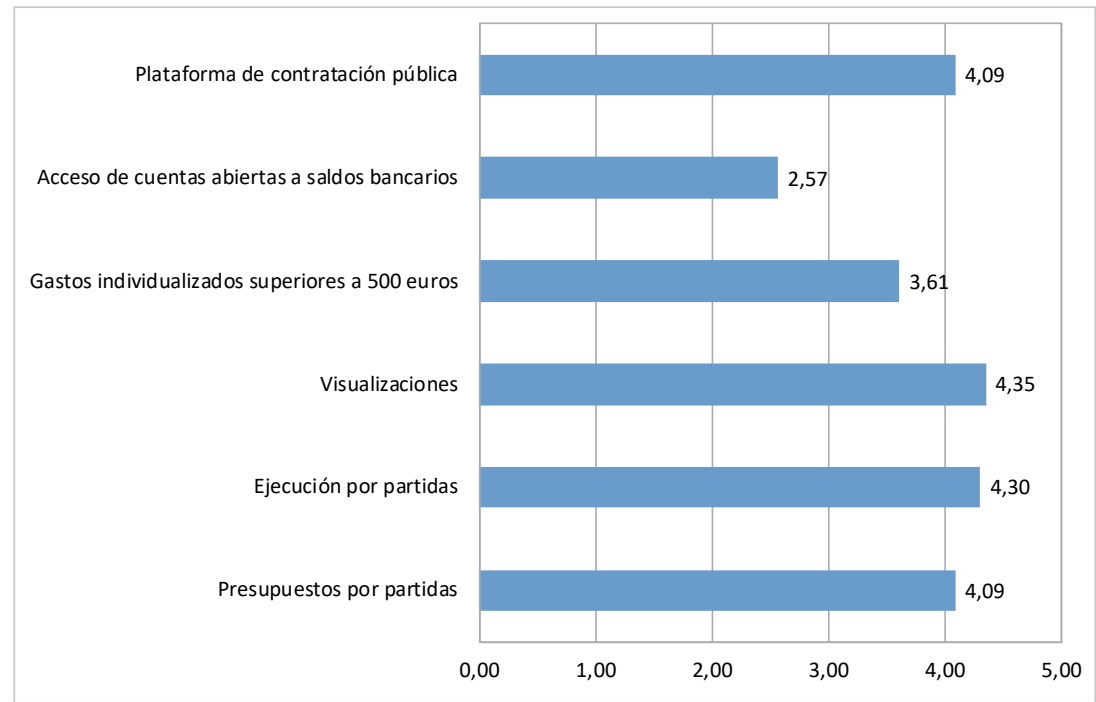

Gráfico 2. Importancia concedida a los contenidos (promedio) para el ciudadano medio de algunos datos e informaciones comúnmente divulgadas, valorando la relevancia en una escala de 1 a 5 entre nada y muy relevante.

Se otorgó la mayor relevancia a las visualizaciones gráficas y a la divulgación de la ejecución de información presupuestaria (en cualquier formato). Destaca el rechazo generalizado al llamado acceso de cuentas abiertas extendido en algunas administraciones españolas en estos últimos años, consistente en divulgar los saldos mantenidos en las entidades bancarias y sus movimientos con carácter periódico. Asimismo, también destaca la escasa importancia concedida a la publicación periódica de listados de gastos superiores a 500 euros, a semejanza de la obligación existente para los municipios británicos desde el inicio de sus programas de datos abiertos. En ningún caso se observaron dispersiones anormales en las respuestas recogidas.

\subsubsection{Grupos de usuarios interesados en la información presupuestaria}

Se incluía en el cuestionario una pregunta en la que se pedía a los responsables que identificaran el interés de distintos grupos de usuarios en la información presupuestaria, valorando en una escala entre 1 y 5 , siendo 1 nada interesado y 5 muy interesado. Con ella se pretendía determinar cuáles eran los grupos a los que se estaba enfocando la información 
generada por la aplicación. Entre las valoraciones obtenidas en este apartado, sin duda la más sorprendente es que los ciudadanos individuales son los menos interesados en la información presupuestaria. Los partidos políticos son, con una amplia diferencia, los más interesados en estos datos, seguidos de los medios de comunicación. Que éstos aparezcan entre los mejor valorados es coherente con la concepción vertical de la transparencia y rendición de cuentas, sirviendo de intermediarios entre ciudadanía y administración. No obstante, nos resulta más difícil de encajar la extraordinaria valoración que reciben los partidos políticos, aunque es evidente que los datos presupuestarios son la materia prima de su trabajo, particularmente en plenos y parlamentos. En todas las categorías las desviaciones típicas son muy similares.

4.1.4. Barreras a la adopción del software de visualización

Por último, en el bloque general se hacía una primera evaluación sobre barreras a la adopción de la aplicación, valorando entre 1 y 5 si la barrera era nada importante o muy importante. En las respuestas recogidas en esta pregunta se manifiesta por primera vez claramente que adoptar esta aplicación no ha sido un problema de dinero, ni tampoco de capacidad tecnológica. Entre las barreras más importantes hay tres claramente organizativas:

- falta de recursos humanos, entendida como personal que se pueda hacer cargo del mantenimiento y actualización;

- dinámicas culturales de la organización (procedimientos habituales de hacer las cosas);

- falta de una estrategia clara en transparencia y rendición de cuentas.

Creemos que estos tres factores pueden formar parte de una misma definición del problema: acciones que se ponen en marcha para reforzar la imagen positiva de transparencia en la organización, sin contar con una planificación clara que permita encauzar recursos de manera sostenida hacia la consecución de unos objetivos claramente definidos. En esta pregunta nos encontramos para cada barrera con desviaciones típicas superiores a las habituales, indicando un menor grado de consenso para todas las valoraciones.

\subsection{Bloque de actitudes individuales}

En este apartado, se ofrecen respuestas a cuestiones de carácter individual sobre la implantación y mantenimiento de la aplicación.

\subsubsection{Creencias sobre el tipo de transparencia generada y experiencias previas}

En esta parte del cuestionario se pretendía conocer cuál era el objetivo principal que debería tener la aplicación. Para ello los encuestados sólo podían elegir una de las opciones disponibles. Siendo la aplicación para la visualización de presupuestos, no ha de ser una sorpresa que la mayoría de los encuestados consideren que mejorar la transparencia financiera y presupuestaria es su principal función. Más interesantes son el resto de respuestas, pues el apoyo de la aplicación en procesos participativos (transparencia participativa) o su uso para localizar
Los ciudadanos individuales son los menos interesados en la información presupuestaria y los partidos políticos los más interesados 
datos particulares de información sobre los ciudadanos (microtransparencia) obtienen porcentajes de respuesta significativos como función principal. Incluso se recoge un pequeño residual de otros usos como función principal que en los comentarios a la respuesta se explican como uso ilustrativo en notas de prensa o campañas de concienciación fiscal. Es evidente que una herramienta no puede tener un sólo objetivo, pero estas respuestas muestran cómo lo que a priori parece una función clara y directa no lo resulta tanto, planteándose otros objetivos principales alternativos. Particularmente transparencia participativa y microtransparencia, a los que podemos considerar como usos más sofisticados ya que entroncan con los objetivos de participación y colaboración propios de los modelos de gobierno abierto, estarían en la línea de lo que cabría esperar de entidades innovadoras que dan pasos proactivos más allá de lo exigido por la normativa.

Se quiso también conocer cuál era la experiencia previa en implementación de datos abiertos y otras aplicaciones de visualización de información que tenían los responsables. Sólo cerca del $40 \%$ de los encuestados respondieron afirmativamente, refiriendo fundamentalmente responsabilidad en la creación y mantenimiento de portales o conjuntos de datos abiertos, principalmente en su misma entidad actual. Por tanto, mayoritariamente, los responsables no habían tenido experiencia previa en el campo de la apertura de datos públicos.

\subsubsection{Utilidad percibida de la aplicación}

Resultaba de interés conocer la percepción de los responsables sobre los beneficios obtenidos por el uso de la aplicación. Por ello, se les facilitó una lista con tres objetivos con respuesta dicotómica sí/no en función del conocimiento que tuvieran sobre la utilización de la misma. Además, se pedía que explicaran alguna situación de uso o por qué este uso no se le había dado. El uso de la aplicación se ha considerado de un modo destacado como beneficioso para la investigación periodística y, ya en menor grado, para pedir explicaciones a la administración o responsables políticos sobre gasto público y acciones de gobierno o gestión. Ambos usos reúnen un amplio consenso con más respuestas afirmativas que negativas. Por el contrario, el uso en procesos de decisión es negado en un mayor porcentaje. Ambos resultados son coherentes con los obtenidos previamente respecto a los usuarios con mayor interés en la información presupuestaria, donde el principal grupo eran los partidos políticos seguidos de los medios de comunicación; y con el principal objetivo de transparencia, donde la transparencia participativa y microtransparencia no resultaban ser los principales pero obtenían tasas de respuesta considerables.

Esto ofrece una doble visión respecto a usos y usuarios apareciendo un primer escenario que comprende a medios de comunicación y grupos políticos que harían uso de la aplicación para buscar y contextualizar información en torno a ingresos, gastos y acciones de la administración en una actividad claramente enmarcada en la rendición de cuentas. En un segundo escenario, más reducido, es un entorno participativo, que seguiría marcado por los mismos usuarios principales pero con el objetivo de ayudar a comprender e ilustrar las acciones de la administración.

Insistimos de nuevo en los resultados obtenidos acerca de los usuarios, pues en los comentarios recogidos de los encuestados hay reiteradas menciones al limitado uso de la ciudadanía por falta de conocimientos básicos presupuestarios y a la necesidad de potenciar la aplicación con algún tipo de campaña informativa sobre su existencia, uso, posibilidades y contenidos para redundar en un efectivo impacto en la rendición de cuentas directa a la ciudadanía. Por tanto, no ha de resultar extraño que el uso de la aplicación venga de otros grupos que realizan tareas representativas o que se encargan de elaborar informaciones con los datos para destinarlos al consumo general.

Adicionalmente, en el apartado Otros se refiere el uso propio de la aplicación para explicaciones y detalles visuales de partidas o comparativas interanuales en documentos de uso interno o para campañas de divulgación sobre determinadas actuaciones. Este empleo no había sido recogido a priori en el cuestionario, pero su tasa de respuesta resulta ser considerable.

\subsubsection{Motivaciones personales}

Con esta pregunta pretendíamos conocer las razones últimas por las que se decide implantar la herramienta, mediante la proyección del comportamiento personal en la atribución del comportamiento de la entidad. Para ello, los responsables debían valorar de 1 a 5, entre nada importante y muy importante, tres motivaciones posibles. A ellas se les sumó 
una pregunta de respuesta dicotómica sí/no sobre mejora de la posición jerárquica o de influencia del responsable tras una exitosa implantación. Entre las motivaciones recogidas en el gráfico 7, existe un amplio consenso en el deseo de lograr la excelencia en la rendición de cuentas y transparencia como principal elemento motivador $y$, en menor medida, el deseo de unirse a un grupo de entidades innovadoras. Por el contrario, la respuesta a la presión social en pro de la rendición de cuentas y transparencia no habría resultado determinante. La desviación típica en las respuestas resulta bastante cambiante. El deseo de excelencia genera amplio consenso $(0,34)$, la unión a un grupo de entidades innovadoras presenta valores normales $(0,94)$, mientras que la respuesta a la presión social muestra amplia variabilidad en las valoraciones con una elevada dispersión (1,35).

Respecto a la carrera profesional, tan sólo un $35 \%$ de los encuestados consideraron que la implantación podría mejorar la posición jerárquica o de influencia en la organización del responsable, por lo que no debemos considerarlo especialmente relevante como factor motivador.

\subsection{Bloque de contextos}

En este apartado se perfila el entorno organizativo y externo de las entidades en estudio.

\subsubsection{Facilidad de implementación, mantenimiento y acceso a la tecno- logía}

Para responder esta cuestión empleamos respuestas tanto del bloque de actitudes individuales (P9) como del bloque de contextos (P11 y P12). Se ha considerado conveniente agruparlas para poder realizar una interpretación conjunta reforzada, como se muestra en el gráfico 8.

En cuanto a la facilidad percibida de uso, se valora como intermedio el grado de dificultad de implantación y mantenimiento técnico de la aplicación en la organización (3,22 puntos sobre 5, siendo 1 muy fácil y 5 muy difícil), habiendo sido en casi el $80 \%$ de los casos contratada con terceros la instalación y puesta en marcha. La mayor dificultad técnica, referida por la mayoría de los encuestados, ha sido trasladar los datos del software de gestión contable y presupuestaria a la aplicación de visualización. Particularmente debido a cambios de partidas entre áreas de presupuesto por reestructuraciones administrativas, lo que requiere de un elevado consumo de recursos humanos para lograr una correcta atribución de datos que permita comparativas interanuales. También se refieren problemas de gobernanza, en concreto, referidos a procedimientos prestablecidos para determinar quién, cómo y cuándo debe resolver la problemática de traslado y proceder a la publicación y actualización de los datos. Destacamos que precisamente los momentos an- 
terior y posterior a estos problemas (esto es, el proceso de obtención de los datos en bruto y la posterior carga de los datos ya depurados) son mencionados como las cuestiones de menor dificultad técnica.

La disponibilidad de hardware o software por parte de la entidad no ha sido considerada una barrera relevante para la implantación. Sin embargo, el modelo de licencia de la aplicación no parece neutral, pues aproximadamente un 55\% de los encuestados afirman que las libertades que garantiza por ser software libre fueron determinantes en su adopción, preguntados como respuesta dicotómica sí/no. También se pidió valorar de 1 a 5, entre nada relevante y muy relevante, tres factores relacionados con el acceso a la tecnología. En este sentido, se calificaron como factores relevantes para la decisión la capacidad de personalización del software y la posibilidad de ampliación o mejora futuras, pero no tanto su coste económico. Para todas las categorías de respuesta de este apartado se obtienen desviaciones típicas elevadas (entre 1,14 y 1,33) salvo para la posibilidad de ampliación y mejora que obtiene una desviación típica que podríamos calificar como normal $(0,95)$.

\subsubsection{Entorno organizativo, marco regulatorio y proactividad}

El objetivo de estas preguntas era conocer el efecto de la estructura organizativa de la entidad en la implantación de la herramienta, así como el entorno exterior determinado por el marco regulatorio o por acciones de voluntariedad y proactividad. Para ello se pidió valorar la importancia de 1 a 5 de una serie de factores organizativos cuyos resultados se muestran en azul en el gráfico 9. El tamaño de la entidad es considerado como más determinante (si bien con una elevada desviación típica), junto con los recursos humanos, las disponibilidades presupuestarias y una formalización organizativa y jerárquica clara. Por el contrario, el menos determinante resultan ser las relaciones externas informales. Debemos ser cautelosos al interpretar estos factores como determinantes, pues el tamaño de la entidad resulta evidente que siempre va a constituir una ventaja, aunque sólo sea por mayor disponibilidad de recursos para unos costes de puesta en marcha con un nivel mínimo fijo. De manera similar, la disponibilidad presupuestaria fue establecida previamente como barrera no excesivamente relevante, por lo que debemos entender que su elevada valoración como determinante se corresponde con un escaso coste relativo a la disponibilidad. En general todas las desviaciones típicas podemos considerarlas como normales, salvo la mencionada para el tamaño de la entidad.

Más interesantes resultan las respuestas respecto al contexto normativo, en rojo en el gráfico 9. En un entorno en el que cada vez más la transparencia se considera una cuestión ligada a la exigencia de una normativa, las razones de proactividad y voluntariedad son consideradas abrumadoramente por los encuestados como las más relevantes para la adopción de la herramienta por encima de cualquier marco regulatorio que imponga obligaciones de divulgación, siendo además su desviación típica muy reducida $(0,44)$. Es evidente que el cumplimiento de las obligaciones legales de transparencia presupuestaria se puede satisfacer facilitando los estados presupuestarios en un simple documento PDF o en datos abiertos, y que disponer de este tipo de aplicaciones de visualización es ir más allá, de un modo que no está contemplado expresamente en ninguna normativa.

\subsubsection{Liderazgo y seguimiento}

También deseamos conocer el tipo de liderazgo que había impulsado la innovación, por ser clave para entender su adopción. Para ello se plantearon cinco tipos de impulsos para los que se solicitó a los responsables que seleccionaran uno exclusivamente como fuente de la iniciativa. Conforme a las respuestas que muestra el gráfico 10, nos encontraríamos mayoritariamente ante una decisión de autoridad, nacida de un responsable político (60,87\% de los casos), y seguido, a mucha distancia, de una decisión de consenso entre distintos roles (21,74\%). En ningún caso se registró el impulso procedente de empleados sin capacidad jerárquica para la decisión.

Por último, hemos creído oportuno conocer si se realizaba un seguimiento del uso de la aplicación. Para ello, se solicitó a los encuestados que valoraran de 1 a 5 (entre muy bajo y muy elevado) su uso, pidiendo que explicaran la valoración otorgada. 
Una vez lanzada y puesta en marcha la herramienta, los encuestados califican su nivel de uso como medio (3,35 sobre 5 , con desviación típica de 1 ). Principalmente por una falta de cultura de acceso a la información que lleva a que sólo la empleen grupos reducidos, combinado con falta de divulgación e instrucción sobre su uso por parte de las administraciones. No obstante, en este seguimiento hemos encontrado varias voces que destacan su valor como medio intermedio entre la dificultad del dato abierto para su tratamiento (formatos de texto estructurado, CSV) y la poca versatilidad para el examen y análisis de los documentos en PDF, por lo que consideran que es una inversión que merece la pena.

\section{Discusión y conclusiones}

Los sistemas de visualización rebajan los niveles de conocimiento requeridos al ciudadano para poder acceder a la información presupuestaria. Por ello, se convierten en un instrumento adecuado para la rendición de cuentas a la ciudadanía, sin perjuicio de otros más formales. Esta investigación ha recogido información mediante cuestionario a los responsables de la puesta en funcionamiento de la aplicación de visualización más popular en las administraciones públicas españolas, sobre su uso e implementación. Hemos obtenido una tasa de respuesta del $71,87 \%$ por lo que estimamos que los resultados pueden ser generalizables.

Nuestros resultados en el bloque general van en la línea de los obtenidos por Gray (2015) y Worthy (2015) para Reino Unido, que describían un escaso interés de los ciudadanos en general por los datos abiertos, con la necesidad de disponer de intermediarios o de elaborar aplicaciones o interfaces que permitan un acceso sencillo a la información y su contextualización. Este estudio se ha basado precisamente en la existencia de esas aplicaciones para un conjunto de datos perfectamente identificados, no habiendo encontrado un consenso claro sobre que haya despertado un especial interés en los ciudadanos, tal y como señala Heald (2012).

En esta línea, también nuestros resultados son coincidentes en la no existencia de un usuario medio, sino más bien de grupos con intereses muy concretos en informaciones particulares. A pesar de ello, la herramienta cumpliría con su cometido, pues estaría creando caminos más sencillos para acceder a unos datos que, de otro modo, requerirían de expertos para su obtención y contextualización. Coincidimos con Clark et al. (2015) en que este tipo de tecnologías digitales destinadas a rendir cuentas al conjunto de ciudadanos acaban en una actividad dependiente de pequeños grupos y en consecuencia su uso se caracterizaría por una cierta inestabilidad según vayan y vengan las necesidades de estos grupos. No deberíamos identificarlo con escaso interés en los datos, sino más bien con la necesidad de que sigan existiendo expertos para crear y contar una historia al público en base a esos datos. Aun resultando más accesibles que en la era pre-digital o en los primeros años de la divulgación online, sigue siendo necesario que sean obtenidos, contextualizados, interpretados y canalizados hacia el usuario lego en la materia. Esto supone una inversión de tiempo y recursos que el ciudadano, destinatario final de la rendición de cuentas, no puede (ni probablemente deba) afrontar en solitario y para la que necesita de intermediarios, normalmente medios de comunicación u otros grupos que realizan la misma función, para canalizar información ya elaborada a los medios. Por tanto, no deberíamos calificar el escaso número de usuarios de estas aplicaciones como un fracaso, sino simplemente indicar que quizá se ha puesto el foco y las expectativas en un grupo de usuarios inexacto, lo que podría contribuir a explicar el fenómeno de caja negra expuesto por Meijer (2013).

También debemos destacar la brecha de expectativas detectada respecto a la importancia de responder a la demanda informativa ciudadana, a la reutilización de datos, y a la oportunidad de la divulgación. Nuestros resultados describen que los responsables otorgan mayor importancia a estos factores de los que creen que sus administraciones les atribuyen, coherente con lo expuesto por García-García y Curto-Rodríguez (2019) de que muchas iniciativas de datos abiertos existen y se mantienen gracias a personas concretas que ponen su empeño personal en ello más allá de cualquier plan o estrategia de transparencia, participación o rendición de cuentas.

Una segunda brecha de expectativas es la referida anteriormente entre el público objetivo teórico (ciudadanos) y mayoritariamente real (medios de comunicación), las creencias previas no se verían totalmente satisfechas lo que creemos que podría frenar en el futuro la expansión de estas herramientas si el objetivo es llegar directamente a la ciudadanía y no uno más amplio de facilitar su acceso a los datos. Este hecho, combinado con las dificultades que pudieran generar los problemas de conciliar la cambiante estructura presupuestaria con la herramienta y con la aspiración declarada de buscar la excelencia para lo que pudiera resultar decepcionante un instrumento que no llega al público en general, refuerza nuestra sensación de que existe un riesgo de freno en su expansión. 
En sentido positivo, merece la pena destacar que entre las variables del entorno no hay grandes rasgos organizativos que de manera concluyente sumen o resten en la posibilidad de adopción. Además, ésta no es dependiente de criterios presupuestarios o tecnológicos, posiblemente debido a la licencia de software libre que además genera expectativas sobre posibilidad de mejoras o adaptaciones futuras. En nuestra opinión, otro rasgo destacable en el entorno, y que entronca con la brecha de expectativas sobre los destinatarios finales, es que el impulso innovador sea mayoritariamente político. Desconocemos hasta que punto se pueden estar generando procesos de adopción impulsados por las modas y el deseo de disponer de aquello que ya disponen otros con independencia de cualquier evaluación previa de objetivos, por ejemplo, conocer a los usuarios reales o lograr un tipo concreto de transparencia. Así se convertiría la adopción de la aplicación en un caso particular del fenómeno de openwashing (Heimstädt, 2017). En cualquier caso, dado el reducido coste de la implementación de estas aplicaciones de visualización y la relevancia de la información ofrecida, creemos que es algo que siempre debería existir y que nos lleva a cuestionar el porqué del escaso número de administraciones que las emplean en su web institucional. En este sentido, líneas futuras de investigación deberían preguntar a cualesquiera destinatarios finales de estas herramientas sobre el uso que realizan de ellas y sus necesidades informativas, de modo que pudieran optimizarse tanto respecto a los usuarios como a las formas de presentar los contenidos.

Uno de los problemas emergentes para los expertos en las políticas de apertura de datos es su gobernanza, esto es, la interacción conjunta de normas, estándares, programas, principios, procesos y decisiones que determinan qué datos se liberan, cómo y por quién (Brandusescu et al., 2019). Este problema, que se manifiesta cuando un proceso de apertura de datos se extiende en volumen y en el tiempo, nos apareció claramente reflejado en la mayor parte de las respuestas en referencia al problema de casación entre la cambiante estructura presupuestaria y las necesidades de estabilidad requeridas por la aplicación para poder realizar comparativas. La falta de un procedimiento claro de en qué momento debe realizarse, si debe formar parte del propio proceso de elaboración de presupuestos, o de quién debe realizarlo, señala claramente un problema de gobernanza que a la larga puede poner en peligro el uso de la herramienta o actuar como barrera a la extensión a nuevas administraciones. Al fin y al cabo se constituye en un coste oculto que se abonará en términos de tiempo de recursos humanos. Como bien señalan Abella, Ortiz-de-Urbina-Criado y De-Pablos-Heredero (2019) las manipulaciones manuales o con herramientas no específicas requieren de tareas repetitivas de escaso valor añadido, que con el tiempo irán abandonándose a medida que el impulso inicial decaiga. Los positivos deseos de proactividad y de lograr la excelencia deberían enfocarse a resolver este problema de gobernanza. Para ello se ha de partir de la formulación de una estrategia de transparencia y rendición de cuentas que enlace con una operativa perfectamente establecida y desarrollando, si fuera necesario, nuevas rutinas, procedimientos o incluso aplicaciones de software que permitan reducir o erradicar estos costes ocultos.

En definitiva, las aplicaciones de visualización presupuestaria constituyen una innovación tecnológica que por su capacidad para reducir las asimetrías informativas deberían estar mayoritariamente extendidas entre las administraciones públicas. No obstante, no debemos caer en ningún tipo de tecnofetichismo que les otorgue propiedades casi mágicas, pues como cualquier tecnología su adopción y uso se verá condicionado por una serie de factores y cualidades que siempre deberán ser controlados para su eficaz desempeño. El Premio Nobel de Economía Ronald Coase (1994) afirmó que los aspectos del sistema económico que son difíciles de medir tienden a descuidarse. Deberíamos extender esta afirmación a los aspectos difíciles de comunicar pues si no, corren el riesgo de ser abandonados por la ciudadanía en su función última de evaluación y control de gobiernos y administraciones.

\section{Referencias}

Abella, Alberto; Ortiz-de-Urbina-Criado, Marta; De-Pablos-Heredero, Carmen (2019). "The process of open data publication and reuse". Journal of the Association for Information Science and Technology, v. 70, n. 3, pp. 296-300. https://doi.org/10.1002/asi.24116

Ajzen, Icek (1985). "From intentions to actions: A theory of planned behavior". Action control: From cognition to behavior, pp. 11-39.

https://doi.org/10.1007/978-3-642-69746-3_2

Ajzen, Icek (1991). "The theory of planned behavior". Organizational behavior and human decision processes, v. 50, n. 2, pp. 179-211.

https://www.sciencedirect.com/science/article/abs/pii/074959789190020T

https://doi.org/10.1016/0749-5978(91)90020-T

Ajzen, Icek (2002). "Residual effects of past on later behavior: Habituation and reasoned action perspectives". Personality and social psychology review, v. 6, n. 2, pp. 107-122.

https://doi.org/10.1207/S15327957PSPR0602_02

Ajzen, Icek; Fishbein, Martin (1977). "Attitude-behavior relations: A theoretical analysis and review of empirical research". Psychological bulletin, v. 84, n. 5, pp. 888-918.

https://doi.org/10.1037/0033-2909.84.5.888

Bagozzi, Richard P.; Davis, Fred D.; Warshaw, Paul R. (1992). "Development and test of a theory of technological learning and usage". Human relations, v. 45, n. 7, pp. 659-686.

https://doi.org/10.1177/001872679204500702 
Baker, Jeff (2012). "The technology - organization - environment framework". Information systems theory, v. 28, pp. $231-245$. https://doi.org/10.1007/978-1-4419-6108-2_12

Brandusescu, Ana; Iglesias, Carlos; Lämmerhirt, Danny; Verhulst, Stefaan (2019). “Open data governance and open governance: Interplay or disconnect?". World Wide Web Foundation.

https://webfoundation.org/2019/02/open-data-governance-and-open-governance-interplay-or-disconnect

Chesbrough, Henry W. (2003). Open innovation: The new imperative for creating and profiting from technology. Boston, Mass: Harvard Business School Press. ISBN: 9781578518371

Clark, Benjamin Y.; Zingale, Nicholas; Logan, Joseph; Brudney, Jeffrey (2015). A framework for using crowdsourcing in government. https://papers.ssrn.com/abstract=1868283

Clarke, Amanda; Francoli, Mary (2014). "What's in a name? A comparison of 'open government' definitions across seven Open Government Partnership members". JeDEM. eJournal of eDemocracy and open government, v. 6, n. 3, pp. $248-266$. https://doi.org/10.29379/jedem.v6i3.227

Coase, Ronald H. (1994). Essays on economics and economists. Chicago: Univ. of Chicago Press. ISBN: 9780226111032

Davis, Fred D. (1989). "Perceived usefulness, perceived ease of use, and user acceptance of information technology". MIS quarterly, v. 13, n. 3, p. 319.

https://doi.org/10.2307/249008

DePietro, Rocco; Wiarda, Edith; Fleischer, Mitchell (1990). "The context for change: Organization, technology and environment". In: Tornatzky, Louis G.; Fleischer, Mitchell. The processes of technological innovation. Lexington Books. ISBN: 9780669203486

Edwards-Schachter, Mónica E.; Matti, Cristian E.; Alcántara, Enrique (2012). "Fostering quality of life through social innovation: A living lab methodology study case". Review of policy research, v. 29, n. 6, pp. 672-692.

https://doi.org/10.1111/j.1541-1338.2012.00588.x

Fishbein, Martin; Ajzen, Icek (1975). Belief, attitude, intention, and behavior: An introduction to theory and research. Reading, Mass: Addison-Wesley Pub. Co. ISBN: 9780201020892

Fuchs, Christian (2010). "Alternative media as critical media”. European journal of social theory, v. 13, n. 2, pp. $173-192$. https://doi.org/10.1177/1368431010362294

García-García, Jesús (2014). “Gobierno abierto: transparencia, participación y colaboración en las administraciones públicas". Innovar, v. 24, n. 54, pp. 75-88.

https://doi.org/10/gcx5v5

García-García, Jesús; Curto-Rodríguez, Ricardo (2019). "El ejercicio de la rendición de cuentas mediante portales de datos abiertos en las comunidades autónomas españolas". IDP. Revista de internet, derecho y política, n. 29. https://doi.org/10.7238/idp.v0i29.3182

Gray, Jonathan (2015). Open budget data: Mapping the landscape. Global Initiative for Financial Transparency (GIFT); Open Knowledge.

http://www.fiscaltransparency.net/eng/resource_open_public.php?/dToOpen=20150902128

Gutiérrez, Miren (2018). Data activism and social change. New York, NY: Springer Berlin Heidelberg. ISBN: 9783319783185

Heald, David (2012). "Why is transparency about public expenditure so elusive?". International review of administrative sciences, v. 78, n. 1, pp. 30-49.

https://doi.org/10.1177/0020852311429931

Heimstädt, Maximilian (2017). "Openwashing: A decoupling perspective on organizational transparency". Technological forecasting and social change, v. 125, pp. 77-86.

https://doi.org/10.1016/j.techfore.2017.03.037

IGAE (1991). "Documento 1: Principios contables públicos". Intervención General de la Administración del Estado, Ministerio de Hacienda, Gobierno de España. Comisión de principios y normas contables públicas.

http://www.igae.pap.hacienda.gob.es/sitios/igae/es-ES/Contabilidad/ContabilidadPublica/Documents/Principios_ Contables_Publicos_Doc_1_a_8.pdf

Kahneman, Daniel (2016). Pensar rápido, pensar despacio. Barcelona: Debate. ISBN: 9788483068618

Lazer, David M. J.; Baum, Matthew A.; Benkler, Yochai; Berinsky, Adam J.; Greenhill, Kelly M.; Menczer, Filippo; Metzger, Miriam J.; Nyhan, Brendan; Pennycook, Gordon; Rothschild, David; Schudson, Michael; Sloman, Steven A.; Sunstein, Cass R.; Thorson, Emily A.; Watts, Duncan J.; Zittrain, Jonathan L. (2018). "The science of fake news". Science, v. 359, n. 6380, pp. 1094-1096.

https://doi.org/10.1126/science.aao2998 
Marangunić, Nikola; Granić, Andrina (2015). "Technology acceptance model: A literature review from 1986 to 2013 ". Universal access in the information society, v. 14, n. 1, pp. 81-95.

https://doi.org/10.1007/s10209-014-0348-1

McClelland, David C. (1987). Human motivation. Cambridge: Cambridge University Press. ISBN: 9780521369510

Meijer, Albert (2013). "Understanding the complex dynamics of transparency". Public administration review, v. 73, n. 3, pp. 429-439.

https://doi.org/10.1111/puar.12032

Mulgan, Geoff (2007). Ready or not?: Taking innovation in the public sector seriously. Nesta. Making Innovation Flourish. https://www.nesta.org.uk/report/ready-or-not-taking-innovation-in-the-public-sector-seriously

Nielsen, Rasmus-Kleis; Graves, Lucas (2017). News you don't believe: Audience perspectives on fake news. Reuters Institute. https://reutersinstitute.politics.ox.ac.uk/sites/default/files/2017-10/Nielsen\&Graves_factsheet_1710v3_FINAL_download.pdf

O’Donell, Guillermo A. (1994). “Delegative democracy”. Journal of democracy, v. 5, n. 1, pp. 55-69.

https://doi.org/10.1353/jod.1994.0010

Rodríguez, Delia (2013). Memecracia: los virales que nos gobiernan. Barcelona: Gestión 2000. ISBN: 9788498752915

Rodríguez-Fernández, Leticia (2019). “Desinformación y comunicación organizacional. Estudio sobre el impacto de las fake news". Revista latina de comunicación social, n. 74, pp. 1714-1728.

https://doi.org/10.4185/RLCS-2019-1406

Rogers, Everett M. (2003). Diffusion of innovations. New York: Simon \& Schuster. ISBN: 9780743222099

Turner, Mark; Kitchenham, Barbara; Brereton, Pearl; Charters, Stuart; Budgen, David (2010). “Does the technology acceptance model predict actual use? A systematic literature review". Information and software technology, v. 52, n. 5, pp. $463-479$. https://www.sciencedirect.com/science/article/abs/pii/S0950584909002055

https://doi.org/10.1016/j.infsof.2009.11.005

Venkatesh, Viswanath; Davis, Fred D. (2000). "A theoretical extension of the technology acceptance model: Four longitudinal field studies". Management science, v. 46, n. 2, pp. 186-204.

https://doi.org/10.1287/mnsc.46.2.186.11926

Vosoughi, Soroush; Roy, Deb; Aral, Sinan (2018). "The spread of true and false news online”. Science, v. 359, n. 6380, pp. 1146-1151.

https://doi.org/10.1126/science.aap9559

Wardle, Claire; Derakhshan, Hossein (2017). Information disorder: Toward an interdisciplinary framework for research and policy making. Council of Europe report DGI (2017)09.

http://edoc.coe.int/en/media/7495-information-disorder-toward-an-interdisciplinary-framework-for-research-andpolicy-making.html

Worthy, Ben (2015). "The impact of open data in the UK: Complex, unpredictable, and political". Public administration, v. 93, n. 3, pp. 788-805.

https://doi.org/10.1111/padm.12166

Anexo 1. Instalaciones activas en mayo de 2019

\begin{tabular}{|c|c|}
\hline \multicolumn{2}{|l|}{ Comunidades autónomas } \\
\hline Aragón & https://presupuesto.aragon.es \\
\hline Castilla-La Mancha & https://castillalamancha.dondevanmisimpuestos.es \\
\hline Euskadi & http://aurrekontuak.irekia.euskadi.eus \\
\hline Islas Baleares & https://pressupostsillesbalears.cat \\
\hline Murcia & https://presupuestos.carm.es \\
\hline Navarra & http://presupuesto.navarra.es \\
\hline \multicolumn{2}{|l|}{ Ayuntamientos } \\
\hline A Coruña & http://ondevanosmeusimpostos.coruna.gal \\
\hline Alhama de Murcia & https://alhama.dondevanmisimpuestos.es \\
\hline Arona & https://arona.dondevanmisimpuestos.es \\
\hline Arroyomolinos & https://misimpuestos.ayto-arroyomolinos.org \\
\hline Barcelona & http://ajuntament.barcelona.cat/estrategiaifinances/pressupostobert \\
\hline Castelló de la Plana & https://onvanelsmeusimpostos.castello.es \\
\hline Cheste & https://cheste.dondevanmisimpuestos.es \\
\hline Eibar & https://dondevanmisimpuestos.eibar.eus \\
\hline El Prat de Llobregat & https://onvanelsmeusimpostos.elprat.cat \\
\hline Las Palmas de Gran Canaria & https://laspalmasgc.dondevanmisimpuestos.es \\
\hline
\end{tabular}




\begin{tabular}{|l|l|}
\hline Madrid & https://presupuestosabiertos.madrid.es \\
\hline Málaga & http://lascuentasclaras.malaga.eu \\
\hline Maó & https://mao.dondevanmisimpuestos.es \\
\hline Montmeló & https://onvanelsmeusimpostos.montmelo.cat \\
\hline Moralzarzal & https://moralzarzal.dondevanmisimpuestos.es \\
\hline Pinto & https://pinto.dondevanmisimpuestos.es \\
\hline Polinyà & https://pressupostos.ajpolinya.cat \\
\hline Santa Coloma de Gramenet & https://gramenet.dondevanmisimpuestos.es \\
\hline Santiago & https://orzamentoaberto.santiagodecompostela.gal \\
\hline Silla & https://silla.dondevanmisimpuestos.es \\
\hline Torrelodones & https://presupuestos.torrelodones.es \\
\hline Vall d'Uixó & https://lavallduixo.dondevanmisimpuestos.es \\
\hline Valladolid & http://cuentasclaras.valladolid.es \\
\hline Vilanova i la Geltrú & http://pressupostos.vilanova.cat \\
\hline Consejos Insulares & \multicolumn{2}{|l|}{} \\
\hline Eivissa & https://eivissa.dondevanmisimpuestos.es \\
\hline Menorca & https://menorca.dondevanmisimpuestos.es \\
\hline
\end{tabular}

\section{Anexo 2. Cuestionario}

\section{Bloque general}

P1. Importancia subjetiva. Valore de 1 a 5 la importancia que usted concede a las siguientes cuestiones a la hora de publicar la información (siendo 1 nada importante y 5 muy importante).

- Que sea respuesta a una demanda ciudadana.

- Que se realice en formatos abiertos para facilitar su reutilización.

- Que se publique en el menor plazo de tiempo posible.

P2. Importancia para la administración. Valore de 1 a 5 la importancia que cree que su entidad concede a las siguientes cuestiones a la hora de publicar la información (siendo 1 nada importante y 5 muy importante).

- Que sea respuesta a una demanda ciudadana.

- Que se realice en formatos abiertos para facilitar su reutilización.

- Que se publique en el menor plazo de tiempo posible.

P3. Importancia de contenidos. ¿Qué tipo de información considera más relevante para la transparencia y rendición de cuentas al ciudadano medio? Valore cada uno de los siguientes tipos en una escala de 1 a 5 (siendo 1 nada relevante y 5 muy relevante):

- Presupuestos de gastos e ingresos, por partidas presupuestarias (en cualquier formato: PDF, CSV, XLS, etc.).

- Ejecución presupuestaria de gastos e ingresos por partidas presupuestarias (en cualquier formato: PDF, CSV, XLS, etc.).

- Visualizaciones gráficas sobre previsión y ejecución de gastos e ingresos.

- Datos individualizados sobre todos los gastos superiores a 500 euros (en cualquier formato: PDF, CSV, XLS, etc.).

- Acceso de cuentas abiertas a los saldos de las cuentas bancarias de la entidad.

- Plataforma de contratación pública (Administración General del Estado o propia de la entidad).

P4. Grupos de usuarios. ¿Qué grupos considera más interesados en los datos presupuestarios? Valore de 1 a 5 (siendo 1 nada interesado y 5 muy interesado):
- Ciudadanos individuales.
- Medios de comunicación.
- Empresas contratistas.
- Asociaciones ciudadanas.
- Partidos políticos.
- Otros (por favor, especifique cual).

P5. Barreras. Valore de 1 a 5 (siendo 1 nada importante y 5 muy importante) la actuación de cada uno de los siguientes factores como barrera a la adopción de la herramienta:

- Resistencia de los responsables jerárquicos.

- Disponibilidades tecnológicas (hardware o software).

- Recursos humanos (personal que se pueda hacer cargo).

- Dinámicas culturales (procedimientos habituales de hacer las cosas).

- Falta de una estrategia clara en transparencia y rendición de cuentas.

- Disponibilidades presupuestarias

\section{Bloque: Actitudes individuales}

P6. Actitud individual: creencias previas. En su opinión ¿Qué tipo de transparencia creará la herramienta que no se alcance por medios de divulgación tradicionales? (marque sólo una):

- Transparencia financiera y presupuestaria (sobre gastos).

- Transparencia participativa (implicar a los ciudadanos en procesos participativos).

- Microtransparencia (permite a los ciudadanos encontrar pequeños datos de información presupuestaria relevantes para ellos).

- Ninguno de los anteriores.

- Otra (por favor, especifique cual):

P7. Experiencia en el uso de la herramienta.

- ¿Con anterioridad a la implantación de la herramienta había colaborado en la implantación de algún tipo de conjunto de datos abiertos o herramienta de visualización en su entidad u otra? Responda Sí/NO

- ¿Podría especificar el tipo de datos abiertos (portal, subconjunto particular, etc.) o herramienta y si fue en su misma entidad u otra? 
P8. Utilidad percibida de la herramienta.

A) ¿Tiene conocimiento de que la herramienta haya sido usada en alguna de las siguientes situaciones? Responda Sí/NO

- Pedir explicaciones a la administración o responsables políticos por su gasto público o acciones de gobierno/gestión.

- Participar en los procesos de decisión de la administración.

- Informaciones periodísticas

- Otros (por favor, especifique cual)

B) Por favor, refiera alguno de los usos anteriores de los que tenga conocimiento o explique por qué cree que no han tenido lugar.

C) ¿Ha existido dentro de su organización algún uso interno de la herramienta de visualización por parte de responsables políticos o administrativos? Responda Sí/NO

D) Si la respuesta anterior fue afirmativa ¿Qué tipo de información se buscó y con qué fin?

P9. Facilidad percibida en la implementación.

A) Valore de 1 a 5 (siendo 1 muy fácil y 5 muy difícil) el grado de dificultad que ha supuesto la implantación y mantenimiento técnico de la herramienta en su organización.

B) ¿Cuál ha sido en su opinión el factor de mayor dificultad técnica (no económica) a la hora de implantar la herramienta?

C) ¿Y el de menor dificultad?

D) La implementación de la herramienta ha sido llevada a cabo principalmente con (marque lo que proceda, sólo una opción):

- Medios propios.

- Contratación con terceros.

- Voluntariado.

P10. Motivación personal.

A) Valore de 1 a 5 (siendo 1 muy poco importante y 5 muy importante) la importancia de los siguientes factores para su entidad a la hora de decidir la implantación de la herramienta:

- Deseo de lograr la excelencia en la rendición de cuentas y transparencia.

- Deseo de unirse a un grupo de entidades innovadoras.

- Respuesta a la presión social de la ciudadanía en pro de la transparencia y rendición de cuentas.

B) Dentro de su entidad ¿Cree que una exitosa implantación de la herramienta puede mejorar la posición jerárquica o de influencia del responsable de la implantación?

\section{Bloque: Contextos}

P11. Capacidad tecnológica. ¿Ha supuesto la disponibilidad de hardware o software en la organización una barrera relevante para la implantación de la herramienta? Valore de 1 a 5 (siendo 1 muy poco relevante y 5 muy relevante).

P12. Acceso a la tecnología.

A) ¿Que la herramienta esté disponible como software libre ha sido determinante para su adopción por razones de coste o personalización? Responda Sí/NO.

B) Valore de 1 a 5 la relevancia de los siguientes factores en la adopción de la herramienta (siendo 1 muy poco relevante y 5 muy relevante)

- Coste económico.

- Capacidad de personalización.

- Posibilidad de ampliación y mejora futura.

P13. Entorno organizativo. Valore de 1 a 5 la importancia de los siguientes factores para implantar la herramienta (siendo 1 muy poco importante y 5 muy importante):

- Tamaño de su entidad (comunidad autónoma, ayuntamiento, cabildo, etc.).

- Descentralización en la toma de decisiones.

- Formalización organizativa y jerarquía claras.

- Relaciones internas informales entre miembros de su organización.

- Relaciones informales de colaboración con entidades ajenas a su organización.

- Recursos humanos en su organización.

- Disponibilidades presupuestarias.

P14. Marco regulatorio. ¿Para implantar la herramienta ha resultado más determinante la existencia de un marco regulatorio que imponía una obligación de divulgación (p.e. normativa sobre transparencia y buen gobierno) o han primado razones de voluntariedad y proactividad en la divulgación? Valore de 1 a 5 (siendo 1 muy poco importante y 5 muy importante):

- Marco regulatorio.

- Voluntariedad y proactividad.

P15. Liderazgo. En su opinión, el impulso a la iniciativa de implementación de la herramienta surgió principalmente de (marque lo que proceda, sólo una opción):

- Autoridad política (presidente, alcalde, consejero, concejal, etc.).

- Autoridad técnica en gestión presupuestaria.

- Autoridad técnica en tecnología de la información.

- Empleados sin capacidad jerárquica para la decisión.

- Consenso entre diferentes roles de los citados.

P16. Seguimiento. ¿Cómo considera el uso de la herramienta de visualización? Valore de 1 a 5 (siendo 1 muy bajo y 5 muy elevado). Si lo desea, puede explicar su valoración en el espacio en blanco provisto a continuación.

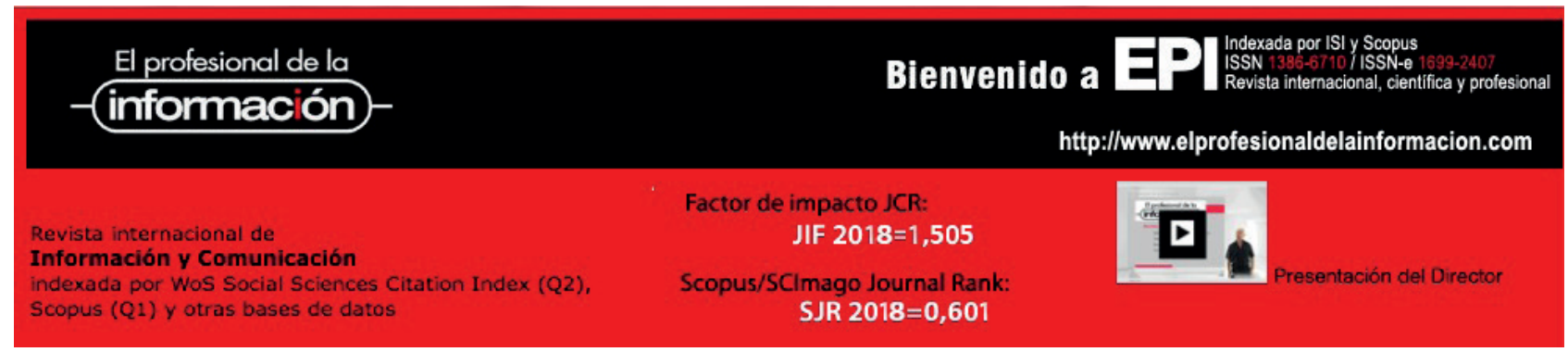

